\title{
KADAR LOGAM TIMBAL (Pb) DALAM DARAH PENJUAL KLEPON
}

\author{
Yayuk Kustiningsih, Noni Fitriyanti Thomas, Nurlailah
}

\author{
Jurusan Analis Kesehatan Poltekkes Kemenkes Banjarmasin \\ JI Mistar Cokrokusumo 4a Banjarbaru \\ e-mail: yayukustiningsih71@gmail.com
}

\begin{abstract}
A kelepon seller is one of the groups susceptible to metal pollution from motor vehicle emissions from the tetraethyl- $\mathrm{Pb}$ and tetramethyl- $\mathrm{Pb}$ combustion products that are always added to motor vehicle fuel. Lead metal has a negative impact on the environment including human health. The first effect of chronic $\mathrm{Pb}$ poisoning before reaching the target organ is the presence of hemoglobin synthesis disorder so that the hemoglobin level decreases. The effect of lead poisoning in the blood can occur if the $\mathrm{Pb}$ content is more $70 \mathrm{ug} / \mathrm{dl}$ or $0.7 \mathrm{ppm}$ which will lead to anemia. This study aims to determine a level of lead metal in the blood of kelepon seller that exceeds the threshold. Descriptive survey research method with cross-sectional design on the sample from 15 respondents. The lead metal $(\mathrm{Pb})$ in the blood is measured using an Atomic Absorption Spectrophotometer (SSA) device. The result of the research shows that there are 13 respondents $(86,7 \%)$ whose $\mathrm{Pb}$ metal content exceeds the blood lead threshold that is $20 \mathrm{ug} / \mathrm{dL}$ or $0,20 \mathrm{ppm}$. The highest level of lead in the blood of the respondents was $0.73 \mathrm{ppm}$ and the lowest was $0.10 \mathrm{ppm}$. Two respondents with lead in blood less than $0.20 \mathrm{ppm}$ are known to always use personal protective equipment while working, even though the working time is 6-10 hours/day. It is advisable to conduct further research by examining $\mathrm{Hb}$ levels and abnormalities of erythrocytes in the blood of the kelepon seller and conducting similar research
\end{abstract}

Keywords: A kelepon seller; Pb metal in blood

Abstrak: Penjual kelepon merupakan salah satu kelompok yang rentan terhadap pencemaran logam timbal yang berasal dari buangan gas kendaraan bermotor dari hasil samping pembakaran tetraetil- $\mathrm{Pb}$ dan tetrametil- $\mathrm{Pb}$ yang selalu ditambahkan dalam bahan bakar kendaraan bermotor. Logam timbal memiliki dampak negatif terhadap lingkungan hidup termasuk kesehatan manusia. Efek pertama keracunan timbal kronis sebelum mencapai target organ adalah adanya gangguan sintesis hemoglobin sehingga kadar hemoglobin menurun. Efek keracunan timbal dalam darah dapat terjadi apabila kandungan $\mathrm{Pb}$ lebih $70 \mathrm{ug} / \mathrm{dl}$ atau 0,7 ppm yang akan mengakibatkan anemia. Penelitian ini bertujuan untuk mengetahui kadar logam timbal dalam darah penjual kelepon yang melebihi ambang batas. Metode penelitian survei deskriptif dengan rancangan cross sectional pada sampel yang berjumlah 15 responden. Logam timbal $(\mathrm{Pb})$ dalam darah diukur menggunakan alat Spektrofototometer Serapan Atom (SSA). Hasil penelitian menunjukkan dari 15 responden yang diperiksa terdapat 13 responden $(86,7 \%)$ yang kandungan logam timbalnya melebihi ambang batas timbal dalam darah yaitu $20 \mathrm{ug} / \mathrm{dL}$ atau $0,20 \mathrm{ppm}$. Kadar timbal dalam darah responden yang paling tinggi adalah $0,73 \mathrm{ppm}$ dan terendah $0,10 \mathrm{ppm}$. Dua responden yang kandungan timbal dalam darahnya kurang dari 0,20 ppm tersebut diketahui selalu menggunakan alat pelindung diri saat bekerja, meskipun waktu kerjanya 6-10 jam/hari. Disarankan untuk melakukan penelitian lebih lanjut dengan memeriksa kadar $\mathrm{Hb}$ dan kelainan eritrosit dalam darah penjual kelepon dan dilakukan penelitian serupa dengan objek yang berbeda.

Kata kunci: penjual kelepon; logam timbal $(\mathrm{Pb})$ dalam darah 


\section{PENDAHULUAN}

Salah satu akibat dari pembangunan di bidang transportasi adalah penambahan jumlah kendaraan bermotor yang sangat pesat, menimbulkan peningkatan pencemaran udara di kota besar yang semakin terasa. Pembakaran bensin dalam kendaraan bermotor penyebab polusi udara kota. Disamping karbon monoksida, juga dikeluarkan nitrogen oksida, belerang oksida, partikel padatan dan senyawa fosfor dan timbal. Senyawa-senyawa ini selalu terdapat dalam bahan bakar dan minyak pelumas mesin. Pembakaran mesin yang tidak sempurna akan menghasilkan banyak bahan yang tidak diinginkan dan meningkatkan pencemaran udara (Hasan, 2012)

Emisi logam timbal $(\mathrm{Pb})$ merupakan hasil samping dari pembakaran yang terjadi dalam mesin-mesin kendaraan. Logam timbal $(\mathrm{Pb})$ yang merupakan hasil dari pembakaran ini berasal dari senyawa tetrametil- $\mathrm{Pb}$ dan tetraetil- $\mathrm{Pb}$ yang selalu ditambahkan dalam bahan bakar kendaraan bermotor dan berfungsi sebagai anti ketuk (anti-knock) pada mesin-mesin kendaraan (Palar, 2004).

Logam timbal $(\mathrm{Pb})$ yang terdapat pada asap kendaraan bermotor akan tersebar di udara dan akan terhirup oleh masyarakat yang ada di jalan raya, seperti penjual kelepon, polisi lalu lintas, dan pengendara bermotor. Secara umum, dampak negatif pencemaran timbal $(\mathrm{Pb})$ sangat tinggi terhadap kelompok masyarakat yang sering dan lama kontak terhadap sumber pencemaran timbal $(\mathrm{Pb})$ yang disebut sebagai kelompok masyarakat resiko tinggi (high risk), salah satunya adalah penjual kelepon, karena mereka setiap hari menjajakan dagangan mereka di pinggir jalan yang sangat rentan terpapar logam timbal $(\mathrm{Pb})$.

Keracunan akibat kontaminasi logam timbal $(\mathrm{Pb})$ bisa menimbulkan berbagai macam hal, antara lain memperpendek umur sel darah merah, menurunkan jumlah sel darah merah dan kadar se-sel darah merah yang masih muda (retikulosit), serta meningkatkan kandungan besi ( $\mathrm{Fe}$ ) dalam plasma darah (Widowati, 2008).

Untuk mengetahui kandungan logam timbal $(\mathrm{Pb})$ di dalam tubuh manusia ditetapkan cara yang akurat dalam bentuk analisis konsentrasi timbal $(\mathrm{Pb})$ di dalam darah atau urine. Kadar logam timbal $(\mathrm{Pb})$ dalam darah dapat merupakan petunjuk langsung jumlah logam timbal $(\mathrm{Pb})$ yang sesungguhnya masuk ke dalam tubuh ( Indra, 2005).

Penelitian di Amerika, didapatkan bahwa timbal mempunyai efek akut terhadap tekanan darah dan menimbulkan hipertensi pada keracunan kronis oleh karena adanya akumulasi timbal di dalam darah pada orang dewasa. Pemaparan terhadap polusi timbal dalam jangka waktu lama akan meningkatkan kadar timbal dalam darah yang kemudian menimbulkan hipertensi (Hasan, 2012).

Hasil penelitian Fakultas Kesehatan Masyarakat Sumatera Utara pada tahun 2005 menunjukkan bahwa kadar timbal $(\mathrm{Pb})$ dalam suspensi darah tukang becak mesin 8 orang $(8,3 \%)<40 \mathrm{mg} / 100 \mathrm{ml}$ dalam kategori normal, 34 orang $(53,4 \%)$ antara $40-80 \mathrm{mg} / 100 \mathrm{ml}$ dalam kategori ditoleransi, 40 orang $(41,7 \%)$ antara $80-120 \mathrm{mg} / 100 \mathrm{ml}$ dalam kategori berlebih dan 14 orang $(14,6 \%)>120$ $\mathrm{mg} / 100 \mathrm{ml}$ dalam kategori berbahaya. Kadar timbal $(\mathrm{Pb})$ dalam spesimen darah tukang becak umumnya tinggi (Indra, 2005).

Jalan Ahmad Yani Km.38 Martapura merupakan Jalan utama yang sering di lalui kendaraan bermotor karena Jalan Ahmad Yani km.38 Martapura merupakan tempat mata pencarian sebagian masyarakat, seperti penjual kelepon yang berjualan di pinggir jalan tersebut. Penelitian ini bertujuan untuk mengetahui kadar logam timbal dalam darah penjual kelepon yang melebihi ambang batas.

\section{BAHAN DAN METODE}

Jenis penelitian yang digunakan adalah survei deskriptif dengan rancangan penelitian Cross sectional yaitu suatu penelitian yang dilakukan dengan cara pengumpulan data dan pemeriksaan yang dilakukan sekaligus dalam waktu bersamaan dengan melakukan uji kuantitatif (Notoatmodjo, 2010).

Populasi pada penelitian ini adalah seluruh penjual kelepon di pinggir jalan Ahmad Yani Km.38 Martapura yang bersedia menjadi responden dengan jumlah 15 orang. Sampel penelitian adalah semua penjual kelepon di pinggir Jalan Ahmad Yani km.38 Martapura.Teknik sampling yang digunakan pada penelitian ini adalah total sampling yaitu 15 penjual kelepon. 
Pemeriksaan kadar logam timbal (Pb) dilakukan di Laboratorium Fakultas Matematika dan IImu Pengetahuan Alam (FMIPA) universitas Lambung Mangkurat Banjarbaru. Alat yang digunakan pada penelitian ini yaitu Spektrofotometer Serapan Atom (SSA) shimadzu AA - 6300 PC, Hollow Cathode Lamp logam timbal $(\mathrm{Pb})$, Water bath, Desikator, Pipet ukur dan volume, Labu ukur. Reagensia yang digunakan yaitu $\mathrm{HCl} 1 \mathrm{~N}, \mathrm{~Pb}$ $\left(\mathrm{NO}_{3}\right)_{2}, \mathrm{KMnO}_{4} 6 \%, \mathrm{H}_{2} \mathrm{SO}_{4} 18 \mathrm{M}, \mathrm{H}_{2} \mathrm{O}_{2} 30 \%$, $\mathrm{HNO}_{3}$ 15,6 M. Variabel penelitian adalah Kadar $\mathrm{Pb}$ dalam darah penjual kelepon di pinggir Jalan Ahmad Yani Km.38 Martapura. Penjelasan mengenai penelitian diberikan kepada responden sebelum persetujuan mengikuti penelitian. Penelitian dilakukan menggunakan sampel darah. Darah yang di ambil adalah darah vena dengan kriteria tertentu dengan menggunakan spuit sebanyak 3 cc dan akan dimasukan di dalam tabung EDTA. Sebelum dilakukan pemeriksaan kadar logam timbal, darah didestruk terlebih dahulu. Pemeriksaan logam timbal menggunakan metode SSA.

\section{HASIL DAN PEMBAHASAN}

Tabel 1. Hubungan masa kerja responden dengan kadar $\mathrm{Pb}$ dalam darah

\begin{tabular}{|c|c|c|c|c|}
\hline \multirow[t]{2}{*}{ No } & \multirow{2}{*}{$\begin{array}{l}\text { MASA } \\
\text { KERJA } \\
\text { (tahun) }\end{array}$} & \multicolumn{2}{|c|}{ KADAR Pb } & \multirow[t]{2}{*}{ JUMLAH } \\
\hline & & $\begin{array}{c}\leq 0.20 \\
\text { ppm }\end{array}$ & $\geq 0.20 \mathrm{ppm}$ & \\
\hline 1. & $<3$ & $0(0 \%)$ & $2(13,3 \%)$ & $13,3 \%$ \\
\hline 2 & $3-5$ & $2(13,3 \%)$ & $8(53,3 \%)$ & $66,6 \%$ \\
\hline 3 & $>5$ & $0(0 \%)$ & $3(20 \%)$ & $20 \%$ \\
\hline & Total & $13,3 \%$ & $86,6 \%$ & $100 \%$ \\
\hline
\end{tabular}

Berdasarkan tabel 1 diatas diketahui bahwa responden yang masa kerjanya kurang dari 3 tahun ada 2 orang(13,3\%) dengan kadar $\mathrm{Pb}$ darahnya $\geq 0,20 \mathrm{ppm}$. Responden yang masa kerjanya antara 3-5 tahun ada 10 orang, 2 orang $(13,3 \%)$ kadar $\mathrm{Pb}$ darahnya kurang dari 0,20 ppm dan 8 orang $(53,3 \%)$ kadar $\mathrm{Pb}$ darahnya lebih dari 0,20 ppm. Responden dengan masa kerja lebih dari 5 tahun ada 3 orang dengan kandungan kadar $\mathrm{Pb}$ dalam darahnya semuanya $\geq 0.2 \mathrm{ppm}$.
Tabel 2. Hubungan waktu kerja dengan kadar $\mathrm{Pb}$ dalam darah

\begin{tabular}{ccccc}
\hline No & Waktu Kerja & \multicolumn{2}{c}{ KADAR Pb } & Jumlah \\
\cline { 3 - 4 }$($ Jam) & $\leq 0.20 \mathrm{ppm}$ & $\geq 0.20 \mathrm{ppm}$ & \\
\hline 1. & $<6$ & 0 & $1(6,6 \%)$ & $6,6 \%$ \\
2 & $6-10$ & $2(13,3 \%)$ & $11(73,3 \%)$ & $86,6 \%$ \\
3 & $>10$ & 0 & $1(6,6 \%)$ & $6,6 \%$ \\
& Total & $13,3 \%$ & $86,5 \%$ & $100 \%$ \\
\hline
\end{tabular}

Berdasarkan tabel 2 diatas diketahui bahwa responden yang bekerja kurang dari 6 jam/hari ada 1 orang $(6,6 \%)$ dengan kandungan $\mathrm{Pb}$ darahnya $\geq 0,20 \mathrm{ppm}$. Responden yang bekerja antara 6-10 jam /hari ada 2 orang $(13,3 \%)$ dengan kandungan $\mathrm{Pb} \leq 0,20 \mathrm{ppm}$ dan 11 orang $(73,3 \%)$ kandungan $\mathrm{Pb}$ darahnya $\geq 0,20 \mathrm{ppm}$. Responden yang bekerja lebih dari 10 jam/hari ada 1 orang $(6,6 \%)$ dengan kandungan $\mathrm{Pb}$ darahnya $\geq$ 0,20 ppm.

Tabel 3. Hubungan Pemakaian APD dengan kadar $\mathrm{Pb}$ dalam darah

\begin{tabular}{|c|c|c|c|c|}
\hline \multirow[t]{2}{*}{ No } & \multirow{2}{*}{$\begin{array}{c}\text { Pemakaian } \\
\text { APD }\end{array}$} & \multicolumn{2}{|c|}{ KADAR Pb } & \multirow[t]{2}{*}{ Jumlah } \\
\hline & & $\begin{array}{l}\leq 0.20 \\
\mathrm{ppm}\end{array}$ & $\geq 0.20 \mathrm{ppm}$ & \\
\hline 1. & $\mathrm{Ya}$ & $2(13,3 \%)$ & $1(6,7 \%)$ & $20 \%$ \\
\hline 2 & $\begin{array}{l}\text { Kadang- } \\
\text { kadang }\end{array}$ & $0(0 \%)$ & $4(26,7 \%)$ & $26,7 \%$ \\
\hline 3 & $\begin{array}{l}\text { tidak } \\
\text { Total }\end{array}$ & $\begin{array}{l}0(0 \%) \\
13,3 \%\end{array}$ & $\begin{array}{c}8(53,3 \%) \\
86,7 \%\end{array}$ & $\begin{array}{l}53,3 \% \\
100 \%\end{array}$ \\
\hline
\end{tabular}

Berdasarkan tabel 3 diketahui bahwa responden yang menggunakan alat pelindung diri (APD)/ masker saat bekerja ada 3 orang (20\%), 2 orang $(13,3 \%)$ kadar $\mathrm{Pb}$ darahnya $\leq$ 0,20 ppm dan 1 orang $(6,7 \%)$ kadar $\mathrm{Pb}$ darahnya lebih dari 0,20 ppm. Responden yang kadang-kadang saja menggunakan APD ada 4 orang $(26,7 \%)$, keempat responden tersebut kadar $\mathrm{Pb}$ darahnya $\geq 0,20 \mathrm{ppm}$. Responden yang tidak menggunakan APD saat bekerja ada 8 orang $(53,3 \%)$, kedelapan responden tersebut kadar $\mathrm{Pb}$ darahnya $\geq$ 0,20ppm. 
Tabel 4 Hasil Pemeriksaan Laboratorium dan Kuisioner

\begin{tabular}{|c|c|c|c|c|c|c|c|c|}
\hline \multirow{2}{*}{$\begin{array}{l}\text { Kode } \\
\text { sampel }\end{array}$} & \multirow{2}{*}{$\begin{array}{c}\text { Jenis } \\
\text { kelamin }\end{array}$} & \multirow{2}{*}{$\begin{array}{l}\text { Umur } \\
\text { (Tahun) }\end{array}$} & \multirow{2}{*}{$\begin{array}{c}\text { Masa } \\
\text { Kerja } \\
\text { (Tahun) }\end{array}$} & \multirow{2}{*}{$\begin{array}{l}\text { Waktu } \\
\text { (Jam) }\end{array}$} & \multicolumn{3}{|c|}{$\begin{array}{c}\text { Pengguna } \\
\text { an APD }\end{array}$} & \multirow{2}{*}{$\begin{array}{c}\text { Kadar } \\
\mathrm{Pb} \\
(\mathrm{ppm})\end{array}$} \\
\hline & & & & & $Y$ & $\mathrm{~T}$ & $\mathrm{~K}$ & \\
\hline 1 & $\mathrm{P}$ & 30 thn & 7 & 8 & & $X$ & & 0,73 \\
\hline 2 & $\mathrm{~L}$ & 31 thn & 7 & 5 & & $x$ & & 0,66 \\
\hline 3 & $\mathrm{P}$ & 40 thn & 3 & 6 & $\mathrm{x}$ & & & 0,15 \\
\hline 4 & $P$ & 32 thn & 4 & 6 & & & $x$ & 0,37 \\
\hline 5 & $\mathrm{P}$ & 38 thn & 3 & 6 & $x$ & & & 0,10 \\
\hline 6 & $\mathrm{P}$ & 38 thn & 5 & 6 & $x$ & & & 0,47 \\
\hline 7 & $\mathrm{~L}$ & 55 thn & 11 & 10 & & & $x$ & 0,60 \\
\hline 8 & $\mathrm{P}$ & 31 thn & 4 & 12 & & & $x$ & 0,38 \\
\hline 9 & $\mathrm{P}$ & 44 thn & 4 & 8 & & & $x$ & 0,25 \\
\hline 10 & $\mathrm{~L}$ & 50 thn & 5 & 7 & & $x$ & & 0,53 \\
\hline 11 & L & 40 thn & 4 & 7 & & $x$ & & 0,48 \\
\hline 12 & $\mathrm{~L}$ & 30 thn & 2 & 9 & & $x$ & & 0,25 \\
\hline 13 & $\mathrm{P}$ & 34 thn & 3 & 7 & & $x$ & & 0,25 \\
\hline 14 & $\mathrm{~L}$ & 45 thn & 5 & 6 & & $x$ & & 0,55 \\
\hline 15 & $\mathrm{P}$ & 45 thn & 2 & 7 & & $x$ & & 0,26 \\
\hline
\end{tabular}

Ket :

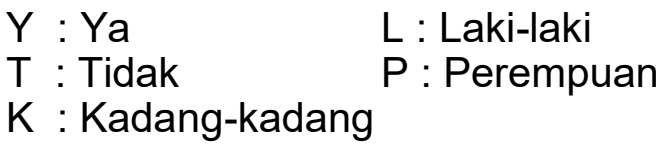

Berdasarkan hasil penelitian didapatkan bahwa dari 15 orang penjual kelepon di pinggir jalan Ahmad Yani Km.38 Martapura terdapat 2 orang $(13,3 \%)$ yang kadar logam timbal dalam darahnya $\leq 0,20$ ppm dan 13 orang $(86,7 \%)$ $\geq$ 0,20ppm. Kadar timbal dalam darah responden yang paling tinggi adalah 0,73 ppm dan terendah 0,10 ppm. Menurut WHO ambang batas timbal dalam darah adalah 20 $\mathrm{ug} / 100 \mathrm{ml}$ atau 0,20 ppm (Mardani, 2005). Efek pertama keracunan timbal kronis sebelum mencapai target organ adalah adanya gangguan sintesis hemoglobin sehingga kadar hemoglobin menurun (Pahlawan, 2014). Efek keracunan timbal dalam darah dapat terjadi apabila kandungan $\mathrm{Pb}$ lebih $70 \mathrm{ug} / \mathrm{dl}$ atau $0,7 \mathrm{ppm}$ yang akan mengakibatkan anemia. Pada kadar 0,3 ppm baru sampai pada tahap menghambat kerja/ mengikat gugus aktif enzim Amino Levulinic Acid Dehidrase (ALAD) yang berperan pada pembentukan hemoglobin

Dilihat dari masa kerja diketahui bahwa masa kerja yang paling banyak adalah 3-5 tahun yaitu sebanyak 10 orang $(66,6 \%)$ dengan kadar timbal dalam darahnya 2 orang $(13,3 \%) \leq 0,20 \mathrm{ppm}$ dan 8 orang $(53,3 \%) \geq$ $0,20 \mathrm{ppm}$. Masa kerja yang kurang dari 3 tahun ada 2 orang $(13,4 \%)$ dengan kadar timbal kurang dari $0,25 \% 1$ orang dan 1 orang kadarnya lebih dari 0,20ppm. Masa kerjanya yang lebih dari 5 tahun ada 3 orang
(20\%) dengan kadar timbal dalam darahnya semua diatas $0,20 \mathrm{ppm}$. Responden yang sering menggunakan APD sebanyak 3 orang $(20 \%)$ kadar logam timbal dalam darahnya lebih rendah dibandingkan dengan yang tidak pernah memakai APD. Jumlah penjual kelepon lebih banyak perempuan yaitu 9 orang $(60 \%)$ dibandingkan laki-laki sebanyak 4 orang (40\%). Penjual kelepon di pinggir jalan merupakan orang yang mempunyai risiko terhadap pencemaran logam timbal (Pb) akibat pengeluaran asap kendaraan bermotor.

Berdasarkan hasil kuisioner terhadap 15 penjual kelepon. Dilihat dari Umur hasil penelitian menunjukkan bahwa umur rata-rata penjual kelepon 30 tahun. Pada penelitian ini umur tidak berpengaruh karena dari hasil kuisioner yang didapatkan umur 30 tahun lebih tinggi kadar logam timbal dalam darahnya, dibandingkan umur 50 tahun, setelah dilihat dari kebiasaannya responden ternyata jarang menggunakan APD. Sedangkan menurut Palar (2004) semakin tua seseorang akan semakin tinggi pula konsentrasi logam timbal $(\mathrm{Pb})$ yang terakumulasi dalam jaringan tubuhnya, karena pada usia tua biasanya aktivitas enzim biotransformase berkurang dan daya tahan organ tertentu berkurang terhadap efek timbal. Menurut Indra (2005) logam timbal $(\mathrm{Pb})$ mempunyai dampak terhadap kesehatan baik kelompok umur dewasa maupun anak-anak, bahkan apabila kadar logam timbal $(\mathrm{Pb})$ dalam darah sudah berada diatas $100 \mathrm{mg} / \mathrm{dl}$ dapat menyebabkan kematian.

Dilihat dari jenis kelamin rata-rata penjual kelepon berjenis kelamin wanita dengan jumlah responden sebanyak 9 orang $(60 \%)$ sedangkan laki-laki sebanyak 6 orang $(40 \%)$. Pada penelitian ini didapatkan 5 orang (33\%) laki-laki yang kadar logam timbal dalam darahnya lebih tinggi dari wanita. Ini dikarenakan masa kerja mereka yang lebih lama. Menurut palar (2004) pekerja wanita lebih mudah terkena paparan dibandingkan laki-laki. Karena wanita lebih rentan dari pada laki-laki, perbedaan faktor ukuran tubuh (fisiologi), keseimbangan hormonal dan perbedaan metabolisme (Suciani 2007). 
Dilihat dari masa kerja diketahui bahwa masa kerja yang paling banyak adalah 3-5 tahun yaitu sebanyak 10 orang $(66,6 \%)$ dengan kadar timbal dalam darahnya 2 orang $(13,3 \%) \leq 0,20$ ppm dan 8 orang $(53,3 \%) \geq$ $0,20 \mathrm{ppm}$. Berdasarkan hasil kuesioner, penjual kelepon yang kadar timbal darahnya kurang dari $0,20 \mathrm{ppm}$ ini selalu menggunakan Alat Pelindung Diri (APD) saat bekerja sedangkan yang lain kadang-kadang saja menggunakan APD.. Masa kerja yang kurang dari 3 tahun ada 2 orang (13,3\%) dengan kadar timbal darahnya lebih dari $0,20 \mathrm{ppm}$. Masa kerja yang lebih dari 5 tahun ada 3 orang $(20 \%)$ dengan kadar timbal dalam darahnya semua diatas 0,20 ppm. Intoksikasi akibat $\mathrm{Pb}$, diklasifikasikan keracunan kronik $\mathrm{Pb}$ yaitu para penderita yang terpapar terus menerus menyebabkan $\mathrm{Pb}$ yang terhirup akan terakumulasi dalam tubuh sampai tingkat tertentu sehingga memberikan tanda-tanda keracunan. Menurut Indra (2005) logam timbal (Pb) yang terdapat di dalam tulang hanya akan bergerak lambat dan secara umum akan meningkat jumlahnya bersamaan dengan waktu terpapar. Logam timbal $(\mathrm{Pb})$ mempunyai waktu paruh dalam darah sangat lambat sekitar 25 hari, pada jaringan lunak 40 hari dan pada tulang 25 tahun (Mifbakhuddin 2010). Jadi apabila semakin lama seseorang bekerja maka darah akan semakin terpapar logam timbal. Menurut Fardiaz (1992), analisis $\mathrm{Pb}$ dalam tulang cukup sulit, maka kandungan $\mathrm{Pb}$ dalam tubuh ditetapkan dengan menganalisis $\mathrm{Pb}$ dalam darah dan urin. Konsentrasi $\mathrm{Pb}$ dalam darah ini merupakan indikator yang lebih baik dibandingkan dalam urin.

Penjual kelepon paling banyak berjualan selama $6-10$ jam/hari yaitu 13 orang $(86 \%)$. Dari 13 orang tersebut, 2 orang $(13,3 \%)$ kadar timbal dalam darahnya $\leq 0$, 20 ppm dan 11 orang (73,3\%) kadar timbalnya $\geq 0,20$ ppm .Penjual kelepon yang berjualan kurang dari 6 jam/hari ada 1 orang $(6,6 \%)$ dan yang berjualan lebih dari 10 jam / hari ada 1 orang $(6,6 \%)$. Dari hasil kuisioner responden, didapatkan 1 orang yang bekerja 5 jam /hari dengan kadar logam timbal lebih tinggi dibandingkan yang bekerja 12 jam/hari. Setelah dilihat dari hasil kuesioner diketahui responden yang berjualan selama 5 jam/hari masa kerjanya lebih lama dibandingkan dengan yang berjualan selama 12 jam/hari. Dari hasil penelitian ini terlihat bahwa jumlah jam kerja kurang berpengaruh dibandingkan dengan masa kerja.

Dari hasil kuisioner 15 responden, yang memakai alat pelindung diri hanya sekitar 3 orang $(20 \%)$. Ada 2 orang $(13,3 \%)$ responden yang kadar timbal darahnya kurang dari 0,20 ppm dan yang 1 orang $(6,7 \%)$ kadarnya lebih dari 0,20 ppm. Responden yang kadangkadang atau tidak pernah menggunakan alat pelindung diri (APD) saat bekerja, kadar timbal dalam darahnya semuanya lebih dari 0,20 ppm. Ini menunjukkan bahwa alat pelindung diri sangat berpengaruh terhadap masuknya logam $\mathrm{Pb}$ dalam tubuh. Hal ini sesuai dengan pernyataan dari A.Yuma, 2014 yang menyatakan bahwa alat pelindung diri mampu menyaring debu dan senyawasenyawa lain (logam $\mathrm{Pb}$ ) hingga 0,5 mikron. Proses masuknya logam timbal $(\mathrm{Pb})$ ke dalam tubuh dapat melalui beberapa jalur, yaitu: melalui udara, makanan atau minuman dan penetrasi pada selaput atau lapisan kulit. Logam timbal $(\mathrm{Pb})$ yang terserap dalam darah berikatan dengan sel darah merah dan akan menghambat proses pembentukan $\mathrm{Hb}$, sehingga seseorang yang mengabsorbsi logam timbal $(\mathrm{Pb})$ di udara, kandungan logam timbal $(\mathrm{Pb})$ dalam darah akan meningkat dan $\mathrm{Hb}$ akan menurun (Wahyu Kurniawan 2008).

\section{KESIMPULAN}

Dari 15 responden yang diperiksa terdapat 13 responden $(86,7 \%)$ yang kandungan logam timbalnya melebihi ambang batas timbal dalam darah yaitu $20 \mathrm{ug} / \mathrm{dL}$ atau $0,20 \mathrm{ppm}$

\section{SARAN}

Disarankan untuk melakukan penelitian lebih lanjut dengan memeriksa kadar $\mathrm{Hb}$ dan kelainan eritrosit dalam darah penjual kelepon dan dilakukan penelitian serupa dengan objek yang berbeda.

\section{DAFTAR PUSTAKA}

Hasan W. (2012). Pencegahan Keracunan Timbal $(\mathrm{Pb})$ Kronis ada Pekerja Dewasa dengan Suplemen Kalsium. Ejournal.undip, 16. Retrieved from http: //ejournal.undip.ac. id/index.php/ jkli/article /view/4139 
Indra C. (2005). Darah Tukang Becak Mesin di Kota Pematang Siantar dan Beberapa faktor yang Berhubungan. Jurnal Unimus, 138.

Malaka, T. (2011). Hubungan Kadar Timbel dalam Darah dengan Kadar Hemoglobin dan Hematokrit pada Petugas Pintu Tol Jagorawi. Jurnal Kesehatan Masyarakat Nasional, 6(1).

Mardani, T. ., Setiyono, P., \& Listyawati, S. (2005). Kadar Timbal (Pb) dalam Darah dan Hubungannya dengan Kadar $\mathrm{Hb}$ Darah Akibat Emisi Kendaraan Bermotor pada Petugas DLLAJ di Kota Surakarta. Bio SMART, 3(1), 60-65.

Mifbakhuddin. (2010). Hubungan Kadar Pb dengan Profil Darah Petugas Operator Stasiun Pengisian Bahan Bakar Umum di Kota Semarang Timur. Jurnal Unimus, 6. Retrieved from http://jurnal.unimus.ac.id/ index.php/jkmi/article/download/59/143

Notoatmodjo, S. (2010). Metodologi Penelitian Kesehatan. Jakarta: Rineka Cipta.

Pahlawan, S. ., \& Keman, S. (2014). Korelasi Kadar Plumbum Darah Dengan Kadar Hemoglobin Dan Hematokrit. Jurnal Kesehatan Lingkungan, 7(2), 159-165.

Palar H. (2004). Pencemaran dan Toksikologi Logam Berat. Jakarta: Rineka Cipta.

Wahyu, K. (2008). Hubungan Kadar Pb dalam Darah Dengan Profil Darah Pada Mekanik Kendaraan Bermotor Di Kota Pontianak. Universitas Diponegoro.

Widowati W. (2008). Efek Toksik Logam. Yogyakarta: Andi Offset.

Yuma, A. (2014). Faktor-Faktor Yang Berpengaruh dengan Kapasitas Vital Paru pada Pekerja Penggilingan Divisi Batu Putih di PT.Sinar Utama Karya. Journal Unnes. 